\title{
A Mechanistic Study on Alkaline Hydrolysis of Y-Substituted Phenyl Benzenesulfonates
}

\author{
Li-Ra Im, Youn-Min Park, and Ik-Hwan Um \\ Department of Chemistry and Nano Science, Ewha Womans University, Seoul 120-750, Korea. E-mail: ihum@ewha.ac.kr \\ Received October 1, 2008
}

\begin{abstract}
Second-order rate constants $\left(k_{\mathrm{OH}^{-}}\right)$have been measured spectrophotometrically for reactions of Y-substituted phenyl benzenesulfonates (1a-h) with $\mathrm{OII}^{-}$in $\mathrm{I}, \mathrm{O}$ containing $20 \mathrm{~mol} \% \mathrm{DMSO}$ at $25.0 \pm 0.1^{\circ} \mathrm{C}$. The Bronstedtype plot is linear with $\beta_{\mathrm{o}}=-0.55$ including the points for the reactions of 2,4 -dinitrophenyl benzenesulfonate (1a) and 4-chloro-2-nitrophenyl benzenesulfonate (1e), indicating that the ortho-nitro group on the leaving aryloxide does not exert steric hindrance in the current reactions. The Ilammett plot correlated with of constants exhibits highly scattered points, while the Ilammett correlation with $\bar{\sigma}$ constants results in a slightly better correlation but still many points deviate from the linearity. In contrast the Yukawa-Tsuno plot shows an excellent linear correlation with $r=0.52$, implying that leaving-group departure occurs at the RDS either in a stepwise mechanism or in a concerted pathway. I Iowever, the stepwise mechanism in which the leaving group departs in the RDS is excluded since the incoming $\mathrm{OII}^{-}$is much more basic and a poorer nucleofuge than the leaving aryloxide. Thus, the alkaline hydrolysis of $\mathbf{1 a - h}$ has been concluded to proceed through a concerted mechanism.
\end{abstract}

Key Words : Alkaline hydrolysis, Rate-determining step, Concerted mechanism, Transition state, YukawaTsuno equation

\section{Introduction}

Nucleophilic substitution reactions of carbon and phosphorus centered esters have been intensively investigated due to the importance in biological processes as well as synthetic applications. ${ }^{1-7}$ However, the corresponding reactions of sulfur centered esters have much less been studied ${ }^{8-13}$ Reactions of aryl benzenesulfonates possessing a weakly basic aryloxide (e.g., 2,4-dinitrophenoxide) have been reported to proceed through competitive $\mathrm{S}-\mathrm{O}$ and $\mathrm{C}-\mathrm{O}$ bond fission pathways (Scheme 1). The regioselectivity has been reported to be influenced strongly by solvents, polarizability of nucleophiles, steric hindrance, etc. ${ }^{8-10}$

The reactions which result in a $\mathrm{C}-\mathrm{O}$ bond fission have been suggested to proceed through a Meisenheimer complex (MC). The rate-determining step (RDS) has been reported to be formation of the $\mathrm{MC}$ on the basis of the fact that the reactivity is independent of the substituent in the sulfonyl moiety. ${ }^{9}$

On the other hand, the reactions which yield the $S-O$ bond-fission products have been reported to proceed through either a concerted mechanism or a stepwise pathway depending on reaction conditions. ${ }^{9-13}$ Williams and his coworkers have concluded that reactions of 4-nitrophenyl 4-

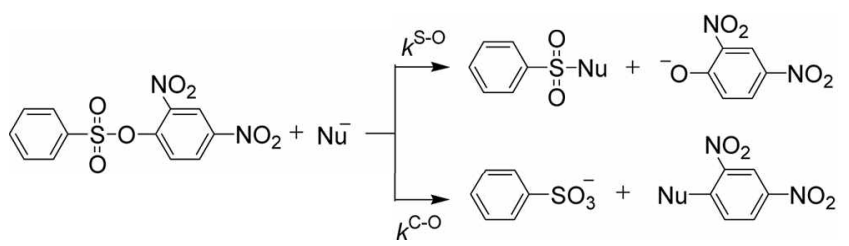

Scheme 1 nitrobenzenesulionate with a series of anionic nucleophiles, whose basicity straddles the leaving 4-nitrophenoxide, proceed through a concerted mechanism on the basis of the linear Bronsted-type plot obtained. ${ }^{11}$ In contrast, Buncel and his coworkers have shown that alkaline ethanolysis of aryl benzenesulfonates proceed through a stepwise mechanism. ${ }^{12}$ The evidence provided was that $\sigma^{\circ}$ constants result in better correlation than $\sigma^{-}$constants in the Hammett treatment of the leaving-group effects. ${ }^{12}$ A similar conclusion has been drawn from reactions of aryl benzenesulfonates with aryloxides in anhydrous ethanol. ${ }^{13}$

We have recently performed reactions of 2,4-dinitrophenyl $\mathrm{X}$-substituted benzenesulfonates with a series of aliphatic primary and secondary amines in $\mathrm{H}_{2} \mathrm{O}$ containing $20 \mathrm{~mol} \%$ DMSO. $^{\text {9ab }}$ It has been shown that the regioselectivity is influenced by the basicity of amine (i.e., the more $\mathrm{S}-\mathrm{O}$ bond fission for the more basic amine) and the nature of substituent $\mathrm{X}$ in the sulfonyl moiety (i.e., the more $\mathrm{S}-\mathrm{O}$ bond fission for the stronger electron withdrawing substituent).

We have now extended our study to reactions of $\mathrm{Y}$ substituted phenyl benzenesulfonates (1a-h) with $\mathrm{OH}^{-}$in $\mathrm{H}_{2} \mathrm{O}$ containing $20 \mathrm{~mol} \%$ DMSO (Scheme 2). We have measured second-order rate constant $\left(\mathrm{kOH}^{-}\right)$and analyzed the kinetic data using Linear Free Energy Relationships such as

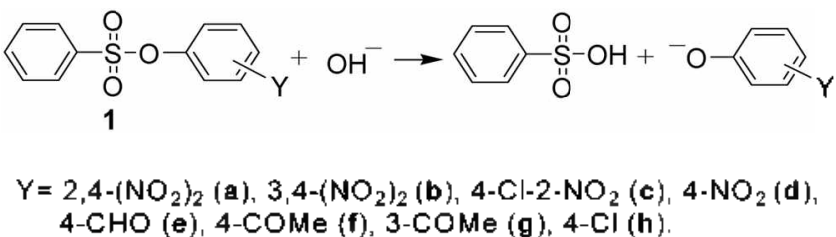

Scheme 2 
Brønsted, Hammett and Yukawa-Tsuno equations to investigate reaction mechanism.

\section{Results and Discussion}

All reactions obeyed first-order kinetics with quantitative liberation of Y-substituted phenoxide ion. Pseudo-first-order rate constants $\left(k_{0 \text { ord }}\right)$ were calculated from the equation $\ln (A$. $\left.-A_{1}\right)=-k_{\text {obsd }} t+C$. The plots of $k_{\text {obsd }}$ is, hydroxide concentration are linear passing through the origin. Thus, the rate equation can be given as eq. (1) and the second-order rate constants $\left(k_{\mathrm{OI}}\right)$ ) have been determined from the slope of the linear plots. The kinetic conditions and results are shown in Table 1 and the $k_{\text {on }}-$ values determined are summarized in Table 2. It is estimated from replicate runs that the uncertainty in the rate constants is less than $\pm 3 \%$.

$$
\text { Rate }=k_{\text {oksd }}[\text { substrate }] \text {, where } k_{\text {otsd }}=k_{\mathrm{OH}^{-}}\left[\mathrm{OH}^{-}\right]
$$

Examination of Steric Hindrance from Bronsted-type Analysis. As shown in Table 2, the second-order rate constant decreases as the substituent $\mathrm{Y}$ in the leaving aryloxide becomes weakly electron withdrawing, i.e., $k_{\mathrm{N}}$ decreases from $7.80 \mathrm{M}^{-1} \mathrm{~s}^{-1}$ to 0.0491 and $0.00207 \mathrm{M}^{-1} \mathrm{~s}^{-1}$ as $\mathrm{Y}$ changes from $2,4-\left(\mathrm{NO}_{2}\right)_{2}$ to $4-\mathrm{NO}_{2}$ and $4-\mathrm{Cl}$, respectively. The effect of substituent $\mathrm{Y}$ on reactivity is illustrated in Figure 1 as a function of $\mathrm{p} K_{\lrcorner}$of the conjugate acid of the leaving aryl-

Table 1. Kinetic Conditions and Results for Reactions of YSubstituted Phenyl Benzenesulfonates (1a-h) with $\mathrm{OH}^{-}$in $80 \mathrm{~mol}$ $\% \mathrm{H}_{2} \mathrm{O} / 20 \mathrm{~mol} \% \mathrm{DMSO}$ at $25.0 \pm 0.1{ }^{\circ} \mathrm{C}$

\begin{tabular}{ccccc}
\hline entry & $\mathrm{Y}$ & {$[\mathrm{OH}] \mathrm{mm}$} & $10^{3} k_{\text {obsi }} / \mathrm{s}^{-1}$ & $\mathrm{n}^{4}$ \\
\hline la & $2.4-\left(\mathrm{NO}_{2}\right)_{2}$ & $3.78-17.5$ & $29.8-138$ & 10 \\
lb & $3.4-\left(\mathrm{NO}_{2}\right)_{2}$ & $17.5-64.3$ & $22.6-82.9$ & 10 \\
lc & $4-\mathrm{Cl}-2-\mathrm{NO}_{2}$ & $17.5-64.3$ & $11.2-41.1$ & 15 \\
Id & $4-\mathrm{NO}_{2}$ & $17.5-64.3$ & $0.886-3.12$ & 10 \\
le & $4-\mathrm{CHO}$ & $38.6-154$ & $0.662-2.71$ & 12 \\
lf & $4-\mathrm{COMe}$ & $17.5-64.3$ & $0.305-1.22$ & 10 \\
lg & $3-\mathrm{COMe}$ & $99.0-198$ & $0.327-0.674$ & 10 \\
lh & $4-\mathrm{Cl}$ & $99.0-198$ & $0.209-0.414$ & 10 \\
\hline
\end{tabular}

Number of runs.

Table 2. Summary of Second-Order Rate Constants $\left(k_{\mathrm{OH}^{-}}\right)$for Reactions of Y-Substituted Phenyl Benzenesulfonates (la-h) with $\mathrm{OH}^{-}$in $80 \mathrm{~mol} \% \mathrm{H}_{2} \mathrm{O} / 20 \mathrm{~mol} \%$ DMSO at $25.0 \pm 0.1^{\circ} \mathrm{C}$.

\begin{tabular}{|c|c|c|c|}
\hline entry & $\mathrm{Y}$ & $\mathrm{p}_{\mathrm{a}}^{\mathrm{Y}-6 \mathrm{LI} 4 \mathrm{IOT}}$ & $10^{2} k_{0 I \Gamma} / \mathrm{M}^{-1} \mathrm{~s}^{-1}$ \\
\hline $1 \mathrm{a}$ & $2,4-\left(\mathrm{NO}_{2}\right)_{2}$ & 3.94 & 780 \\
\hline 1b & $3,4-\left(\mathrm{NO}_{2}\right)_{2}$ & 5.60 & 129 \\
\hline 1c & $4-\mathrm{Cl}-2-\mathrm{NO}_{2}$ & 6.92 & 62.2 \\
\hline 1d & $4-\mathrm{NO}_{2}$ & 7.79 & 4.91 \\
\hline 1e & 4-CHO & 8.45 & 1.73 \\
\hline lf & 4-CoMe & 8.94 & 1.94 \\
\hline $1 \mathrm{~g}$ & 3-COMe & 10.39 & 0.350 \\
\hline $1 \mathrm{~h}$ & $4-\mathrm{Cl}$ & 10.63 & 0.207 \\
\hline
\end{tabular}

The $p K_{\mathrm{s}}$ value of phenols in 20 mol $\%$ DMSO was calculated from the equation $\mathrm{pK}_{\mathrm{a}}^{30 \% \mathrm{D} M N \mathrm{O}}=1.27_{\mathrm{p}} K_{\mathrm{a}}^{\mathrm{T}}{ }^{\mathrm{T} O \mathrm{O}}-1.28$ with the known $\mathrm{p} K_{\mathrm{a}}$ values of phenols in $\mathrm{H}_{2} \mathrm{O}$ (see tef. 14).

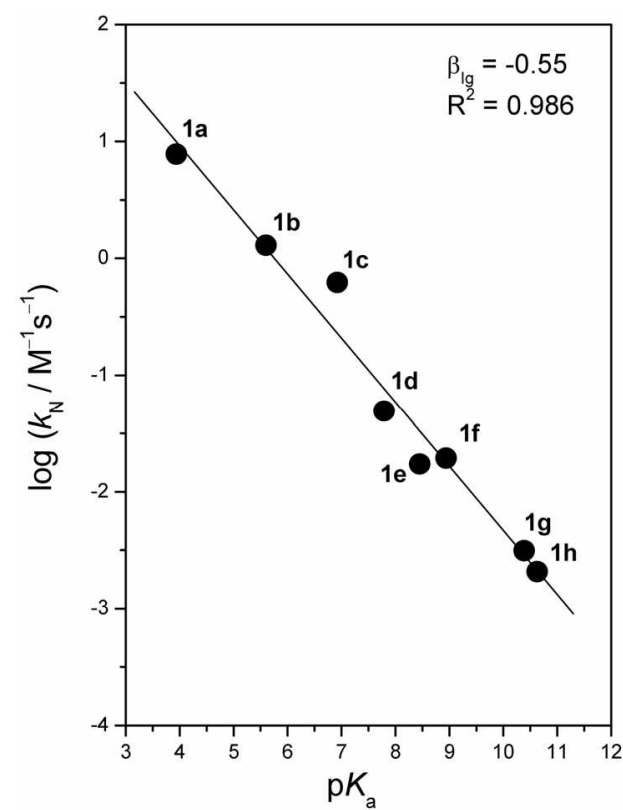

Figure 1. Bronsted-type plot for reactions of Y-substituted phenyl benzencsulfonates (1a-h) with $\mathrm{OH}^{-}$in $80 \mathrm{~mol} \% \mathrm{H}_{2} \mathrm{O} / 20 \mathrm{~mol} \%$ DMSO at $25.0 \pm 0.1^{\circ} \mathrm{C}$. The identity of the numbers is given in Table 2.

oxide. The Bronsted-type plot for the reactions of $\mathbf{1 a - h}$ is linear with $\beta_{e}=-0.55$. It is noted that $1 \mathrm{a}$ and $1 \mathrm{c}$ do not exhibit negative deviations from the linearity although they have a nitro group on the ortho-position of the leaving phenoxide.

It has often been reported that carboxylic esters possessing an ortho-nitrophenoxide as a leaving group (e.g., 2,4-dinitrophenyl acetate, benzoate, 2-furoate, and thiophene-2-carboxylate) exhibit negative deviations from Brønsted-type plots. ${ }^{15.16}$ Steric hindrance exerted by the ortho-nitro group has been suggested to be responsible for the negative deviation, since the ortho-nitro group on the leaving aryloxide would cause steric hindrance. ${ }^{15.16}$ The fact that 1 a and $1 \mathrm{c}$ do not exhibit negative deviations suggests that the steric hindrance is absent in the current sulfonate system. A similar result has been reported for nucleophilic substitution reactions of Y-substituted phenyl diphenylphosphinates including 2,4-dinitrophenyl diphenylphosphinates with piperidine, $\mathrm{OH}^{-}$, and ethoxide jon, indicating that steric hindrance is also absent for the reactions of the phosphorus esters. ${ }^{7 a-d}$

One can suggest that at least two factors are responsible for the absence of the steric hindrance in the reactions of the sulfur and phosphorus centered esters, i.e, the size and hybridization type of the electrophilic centers. The size of the electrophilic center of the sulfonate (i.e., $\mathrm{O}=\mathrm{S}=\mathrm{O}$ ) and phosphinate esters (i.e., $\mathrm{P}=\mathrm{O}$ ) is much larger than that of the carboxylate esters (i.e., $\mathrm{C}=\mathrm{O}$ ). One might expect that steric hindrance would not be significant for the reaction of substrates possessing a large electrophilic center. The type of hybridization of the electrophilic center is also considered to be responsible for the absence of steric hindrance in the phosphorus and sulfur centered electrophiles. The hybridization of the carboxylic esters in the ground state (GS) is $\mathrm{sp}^{2}$ 
which becomes $\mathrm{sp}^{3}$ in the transition state (TS). Accordingly, the TS for the reactions of carboxylic esters becomes more crowded than the GS. In contrast, the hybridization of sulfur and phosphorus centered esters changes from tetrahedral in the GS to trigonal bipyramidal in the TS. Accordingly, the TS for the reactions of the current benzenesulfonate system becomes less crowded than the GS. This argument is consistent with the fact that 1a and 1c do not exhibit a negative deviation from the linear Brensted-type plot.

Determination of Reaction Mechanism. The secondorder rate constant $\mathrm{kon}^{-}$can be expressed as eq. (2) under the assumption of steady-state approximation for reactions which proceed through a stepwise mechanism with an intermediate. Then, eq. (2) becomes eq. (3) or eq. (4) depending on the RDS.

$$
\begin{aligned}
& k_{\mathrm{OH}^{-}}=k_{1} k_{2} /\left(k_{-1}+k_{2}\right) \\
& k_{\mathrm{OII}^{-}}=k_{1} k_{2} / k_{-1}, \text { when } k_{-1} \gg k_{2} \\
& k_{\mathrm{OH}^{-}}=k_{1}, \text { when } k_{-1} \ll k_{2}
\end{aligned}
$$

It is apparent that the electronic nature of the substitutent $\mathrm{Y}$ in the leaving group influences the microscopic rate constants $k_{1}, k_{2}$, and $k_{-1}, i . e$, the $k_{1}$ and $k_{2}$ values would increase, while the $k_{-1}$ value would decrease as substituent $Y$ becomes a stronger electron withdrawing group (EWG). However, the effect of leaving-group substituent $\mathrm{Y}$ on $k_{2}$ would be more significant than on $k_{1}$ and $k_{-1}$, since $\mathrm{Y}$ is located directly on the leaving aryloxide. Accordingly, one might expect a large negative $\beta_{2}$ value for reactions in which $k_{2}$ is the RDS but a small one for those in which $k_{1}=\mathrm{RDS}$. Thus, the magnitude of $\beta_{3}$ values has been taken as a measure of reaction mechanism, e.g., $\beta_{8}$ is $c a .-0.8$ or larger for reactions whose RDS is the $k_{2}$ step but $c a .-0.4$ or smaller for reactions in which $k_{1}=\mathrm{RDS}^{1+4}$ The $\beta_{\mathrm{g}}$ value of -0.55 is typical for reactions which proceed through a concerted mechanism. ${ }^{1-7}$ In fact, we have recently reported that $\beta_{g}$ values of $-0.6 \pm 0.1$ for reactions which proceed concertedly $(e, g$, nucleophilic substitution reactions of Ysubstituted phenyl diphenylphosphinates and diphenylphosphinothioates with amines and anionic nucleophiles such as $\mathrm{OH}$ and ethoxide ion), ${ }^{7}$ while $\beta_{\text {gg }}$ values of -1.2 or larger for reactions in which $k_{2}=\mathrm{RDS}(e . g$., aminolysis of Ysubstituted phenyl benzoates). ${ }^{+}$

As shown in Figure 1, the $\beta_{\mathrm{g}}$ value for the reactions of 1:a$\mathbf{h}$ is -0.55 . Thus, one can propose that the current reactions of Y-substituted phenyl benzenesulfonates with $\mathrm{OH}^{-}$proceed through a concerted mechanism. To support our proposal, Hammett plots have been constructed using $\sigma^{\circ}$ and $\sigma^{-}$ constants as in the following section. It is noted that the points for the reactions of 1a and 1c are excluded in the Hammett plots, since they have an wrho-substituent whose $\sigma^{-}$or $\sigma^{\circ}$ values are not known.

Hammett Correlations with $\sigma^{\circ}$ and $\sigma$ Constants. If the current reaction proceeds through a stepwise mechanism instead of a concerted pathway, the structure of the intermediate should be similar to 2 as illustrated below. It is noted that the incoming hydroxide and leaving aryloxide occupy the apical positions of the trigonal bipyramidal intermediate $\mathbf{2}$.

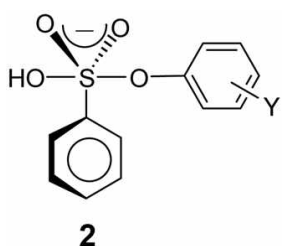

Then the reaction would proceed through either TS, or $\mathrm{TS}_{2}$ depending on the RDS. TS ${ }_{1}$ represents the TS structure when formation of intermediate 2 is the RDS, while $\mathrm{TS}_{2}$ applies to the TS structure when breakdown of 2 occurs in the RDS.
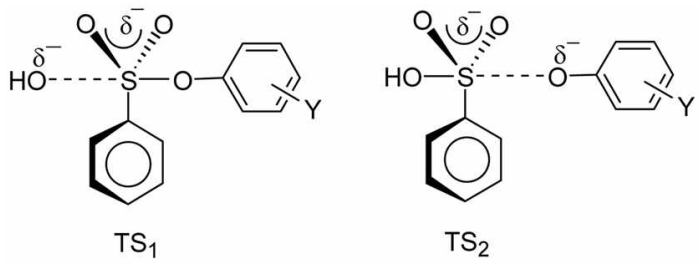

In $\mathrm{TS}_{1}$, the negative charge is delocalized on the incoming hydroxide and the two oxygen atoms of the sulfonyl moiety, but clearly not on the oxygen atom of the leaving $\mathrm{ArO}^{-}$since leaving-group departure is not advanced at all. In this case, one might expect a good Hammett correlation with $\sigma^{\circ}$ constants. As shown in Figure 2, the Hammett plot correlated with $\sigma^{\circ}$ constants demonstrates highly scattered points, indicating that the current reaction does not proceed through $\mathrm{TS}_{1}$.

If the current reactions proceed through a stepwise mechanism with $\mathrm{TS}_{2}$, a partial negative charge develops on the oxygen atom of the leaving aryloxide. Since such a negative

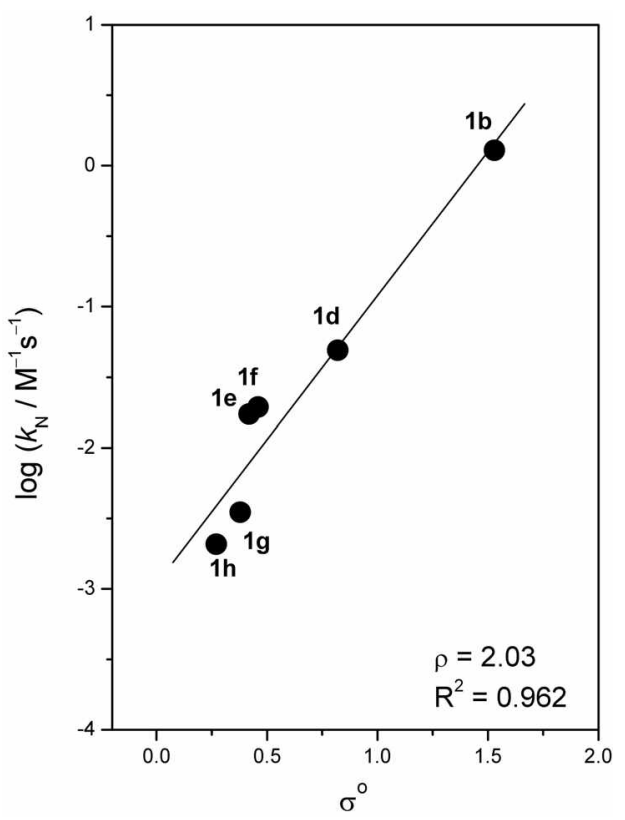

Figure 2. Hamınctt plot corrclated with $\sigma^{\circ}$ constants for reactions of Y-substituted phenyl benzenesulfonates (1b and $\mathbf{1 d - h}$ ) with $\mathrm{OH}^{-}$ in $80 \mathrm{~mol} \% \mathrm{H}_{2} \mathrm{O} / 20 \mathrm{~mol} \% \mathrm{DMSO}$ at $25.0 \pm 0.1^{\circ} \mathrm{C}$. The identity of the numbers is given in Table 2 . 


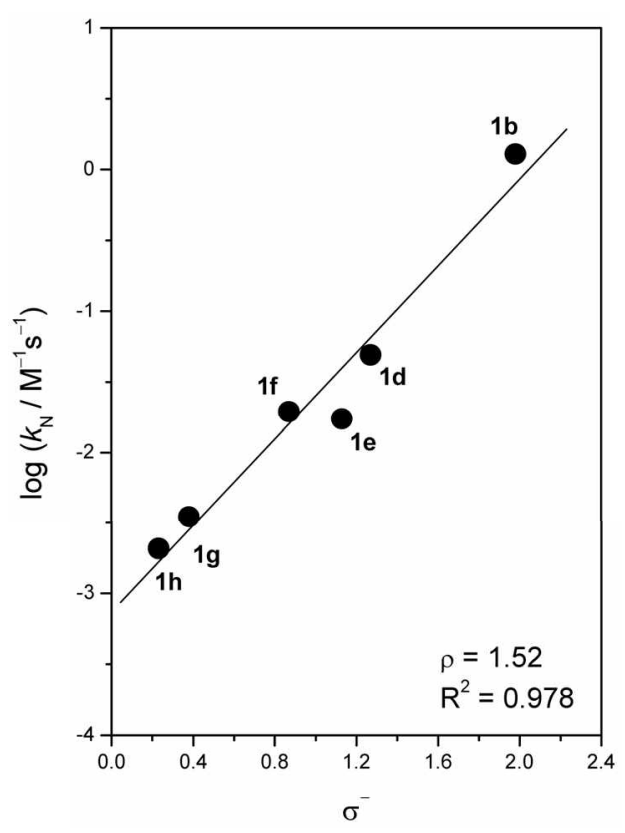

Figure 3. Hammett correlation with $\sigma$ constants for reactions of Y-substituted phenyl benzenesulfonates (1b and $\mathbf{1 d - h}$ ) with $\mathrm{OH}^{-}$in $80 \mathrm{~mol} \% \mathrm{H}_{2} \mathrm{O} / 20 \mathrm{~mol} \%$ DMSO at $25.0 \pm 0.1{ }^{\circ} \mathrm{C}$. The identity of the numbers is given in Table 2 .

charge can be delocalized on the substituent $\mathrm{Y}$ through resonance interaction, one can expect that $\sigma^{-}$constants should result in a good Hammett correlation. As shown in Figure 3, the Hammett plot conrelated with $\sigma^{-}$constants results in only a slightly better correlation than that with $\sigma^{\circ}$ constants (e.g., $\mathrm{R}^{2}=0.979$ in Figure 3 vs. $\mathrm{R}^{2}=0.961$ in Figure 2). However, the Hammett plot also exhibits scattered points, indicating that the reactions do not proceed through $\mathrm{TS}_{2}$ either. Accordingly, one can also exclude $\mathrm{TS}_{2}$ in which the RDS is departure of the leaving aryloxide. This idea can be further supported by the fact that $\mathrm{OH}^{-}$is much more basic and a poorer nucleofuge than the leaving aryloxide.

Yukawa-Tsuno plot and TS structure. We have recently shown that the Yukawa-Tsuno equation (eq. 5) is highly informative to investigate reaction mechanisms. ${ }^{4.7}$ The magnitude of the $r$ value in eq. (5) represents the resonance demand of the reaction center or the extent of resonance contribution while the term $\left(\sigma^{-}-\sigma^{\circ}\right)$ is the resonance substituent constant that measures the capacity for $\pi$ delocalization. ${ }^{17}$

$$
\log k^{\mathrm{x}} / k^{\mathrm{I}}=\rho\left[\sigma^{\circ}+r\left(\sigma^{-}-\sigma^{\circ}\right)\right]
$$

Thus, Yukawa-Tsno plot has been constructed for the reactions of $\mathbf{1 b}$ and $1 \mathrm{~d}-\mathrm{h}$ with $\mathrm{OH}^{-}$. As shown in Figure 4, the Yukawa-Tsuno plot exhibits an excellent linear correlation $\left(\mathrm{R}^{2}=0.994\right)$ with $r=0.52$. The best correlation would be obtained with $\sigma^{-}$constants when $r=1$ or with $\sigma^{\circ}$ constants when $r=0$. Since the $r$ value determined in this study is neither 0 nor 1 , the Yukawa-Tsuno plot exhibits the best linear correlation.

The $r$ value of 0.52 clearly indicates that a partial negative charge develops on the oxygen atom of the leaving aryl-

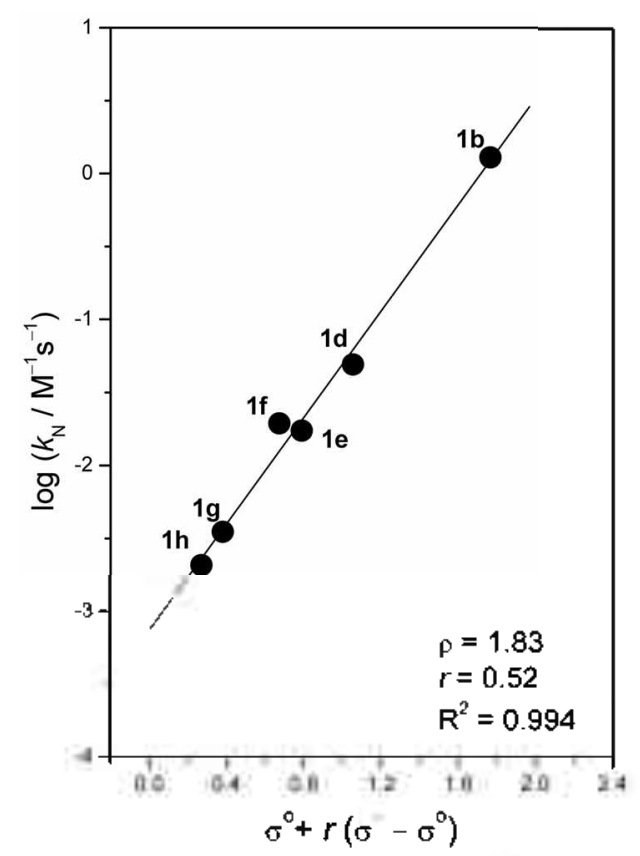

Figure 4. Yukawa-Tsuno plot for reactions of Y-substituted phenyl benzenesulfonates (lb and $\mathbf{l d}-\mathbf{h}$ ) with $\mathrm{OH}^{-}$in $80 \mathrm{~mol} \% \mathrm{H}_{2} \mathrm{O} / 20$ mol \% DMSO at $25.0 \pm 0.1{ }^{\circ} \mathrm{C}$. The identity of the mumbers is given in Table 2 .

oxide. Thus, one can suggest that the reaction proceeds either through $\mathrm{TS}_{2}$ or $\mathrm{TS}_{3}$. However, $\mathrm{TS}_{2}$ has already been excluded as a TS structure in the current reactions on the basis of the fact that $\mathrm{OH}^{-}$is much more basic and a poorer nucleofuge than the leaving aryloxide. Accordingly, one can conclude that the current reactions proceed through a concerted mechanism with a TS structure similar to $\mathrm{TS}_{3}$, in which the partial negative charge on the oxygen atom of the leaving aryloxide can be delocalized on the substituent $\mathrm{Y}$ through resonance interaction. This is consistent with the preceding proposal that the reactions of 1a-h with $\mathrm{OH}^{-}$ proceed through a concerted mechanism on the basis of the $\beta_{\text {o v }}$ value of -0.55 .

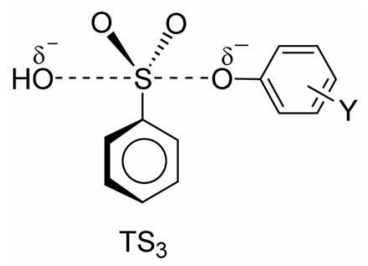

\section{Conclusions}

The current study has allowed us to conclude the following: (1) The Brønsted-type plot for the alkaline hydrolysis of 1:-h is linear with $\beta_{\mathrm{gg}}=-0.55$ including the points for the reactions of $1 \mathrm{a}$ and $1 \mathrm{c}$ which possess an ortho-nitro group on the leaving aryloxide, indicating that steric hindrance is absent in the current reactions. (2) The linear Brønsted-type plot with $\beta_{\mathrm{g}}=-0.55$ has been taken as evidence for a concerted mechanism. (3) The Hammett plot correlated with $\sigma^{\circ}$ constants exhibits highly scattered points, while the 
Hammett correlation with $\sigma^{-}$constants results in only a slightly better correlation. (4) In contrast, the Yukawa-Tsuno plot shows an excellent linear correlation, implying that the leaving group departs in the RDS either in a stepwise mechanism or in a concerted pathway. (5) However, the stepwise mechanism in which the leaving group departs in the RDS has been excluded since the incoming $\mathrm{OH}^{-}$is much more basic and a poorer nucleofuge than the leaving aryloxide. Thus, the alkaline hydrolysis of 1a-h has been concluded to proceed through a concerted mechanism.

\section{Experimental Section}

Materials. Compounds 1a-h were readily prepared from reactions of benzenesulfonyl chloride with Y-substituted phenols in the presence of triethylamine as a base catalyst in anhydrous ether as reported previously. ${ }^{9}$ Other chemicals used were of the highest quality available. The reaction medium was $\mathrm{H}_{2} \mathrm{O}$ containing $20 \mathrm{~mol} \%$ DMSO due to low solubility of 1a-h in pure $\mathrm{H}_{2} \mathrm{O}$. Doubly glass distilled water was further boiled and cooled under nitrogen just before use.

Kinetics. The kinetic study was performed with a UV-vis spectrophotometer equipped with a constant temperature circulating bath to maintain the temperature in the reaction cell at $25.0 \pm 0.1{ }^{\circ} \mathrm{C}$. The reaction was followed by monitoring the appearance of the leaving Y-substituted phenoxide ion. All the reactions were carried out under pseudo-firstorder conditions in which hydroxide concentrations were at least 20 times greater than the substrate concentration. All solutions were prepared freshly just before use under nitrogen, and transferred by using gas-tight syringes. Typically, reactions were initiated by adding $5 \mu \mathrm{L}$ of a $0.02 \mathrm{M}$ solution of the substrate in $\mathrm{CH}_{3} \mathrm{CN}$ by a $10 \mu \mathrm{L}$ syringe to a $10 \mathrm{~mm}$ quartz UV cell containing $2.50 \mathrm{~mL}$ of the thermostatted reaction mixture made up of solvent and aliquot of $\mathrm{NaOH}$ stock solution.

Product Analysis. Y-Substituted phenoxide was liberated quantitatively and identified as one of the products by comparison of the UV-vis spectrum at the end of reaction with the authentic sample under the experimental condition. Our previous study has shown that alkaline ethanolysis of Y-substituted phenyl benzenesulfonates including $\mathrm{Y}=2,4-$ $\left(\mathrm{NO}_{2}\right)_{2}$ proceeds exclusively through the $\mathrm{S}-\mathrm{O}$ bond fission. ${ }^{9 \mathrm{c} .13}$ Accordingly, it is assumed that the current alkaline hydrolysis also proceeds through the $\mathrm{S}-\mathrm{O}$ bond fission exclusively since both $\mathrm{C}-\mathrm{O}$ and $\mathrm{S}-\mathrm{O}$ bond fissions result in the same products.

Acknowledgments. This work was supported by a grant from Korea Research Foundation (KRF-2005-015-C00256). L. R. Im and Y. M. Park are also grateful for the BK 21 Scholarship.

\section{References}

1. (a) Gresser, M. J.; Jencks, W. P. J. Am. Chem. Soc. 1977, 99, 69636970. (b) Gresser, M. J.; Jencks, W. P. J. Am. Chem. Soc, 1977, 99, $6970-6980$.
2. (a) Castro, E. A.; Campodonico, P. R.; Contreras, R.; Fuentealba, P.; Santos, J. G; Leis, J. R.; Garcia-Rio, L.; Saez, J. A.; Domingo, L. R. Tetrahedron 2006, 62, 2555-2562. (b) Castro, E. A.; Gazitua, M.; Santos, J. G. J. Org. Chen. 2005, 70, 8088-8092.

3. (a) Hoque, M. E. U.; Dey, S.; Guha, A. K.; Kim, C. K.; Lee, B. S.; Lee, H. W.J. Org. Chem. 2007, 72, 5493-5499. (b) Oh, H. K.; Oh, J. Y.; Sung, D. D.; Lee, I. J. Org. Chem. 2005, 70, 5624-5629. (c) Lee, H. W.; Guha, A. K.; Kim, C. K.; Lee, I. J. Org. Chem. 2002. 67, 2215-2222. (d) Hoque, M. E. U.; Dey, N. K.; Guha, A. K.; Kim, C. K.; Lee, B. S.; Lee, H. W. Bull. Korean Chem. Soc. 2007, 28, 1797-1802. (e) Hoque, M. E. U.; Lee, H. W. Bull. Korean Chem. Soc. 2007, 28, 936-940.

4. (a) Um, I. H.; Park, Y. M.; Fujio, M.; Mishima, M.; Tsuno, Y. J. Org. Chen. 2007, 72, 4816-482I. (b) Um, I. H.; Hwang, S. J.; Baek, M. H.; Park, E. J. J. Org. Chen. 2006, 7/, 9191-9197. (c) Um, I. H.; Ko, S. H.; Bae, S. K. J. Org. Chem. 2006, 71, 58005803. (d) Um, I. H.; Lee, H. W.; Nagano, Y.; Fujio, M.; Tsuno, Y. J. Org. Chem. 2005, 70, 4980-4987.

5. (a) Han, X.; Balakrishnan. V. K.; Buncel. E. Langnttir 2007, 23 , 6519-6525. (b) Han, X.; Balakrishnan, V. K.; van Loon, G. W. Buncel, E. Langmtir 2006, 22, 9009-9017. (c) Cheung, J. C. F.; Park, Y. S.; Smith, V. H.; van Loon, G.; Buncel, E.; Churchill, D. Can. J. Chem. 2006, 84, 926. (d) Churchill, D.; Cheung, J. C. F.; Park, Y. S.; Smith, V. H.; van Loon, G.; Buncel, E. Can. J. Chem. 2006, 84, 702-708.

6. (a) Cleland, W. W.; Hengge, A. C. Chem. Rev. 2006, 106, 32523278. (b) Hengge, A. C. Actr. Phys. Org. Chem. 2005, 40, 49-108. (c) Catrina, I.; O'Brien, P. J.; Purcell, J.; Nikolic-Hughes, I.; Zalatan, J. G.; Hengge, A. C.; Herschlag, D. J. Am. Chem. Soc. 2007, 129, 5760-5765. (d) Rawlings, J.; Cleland, W. W.; Hengge, A. C. J. Am. Chem. Soc, 2006, 128, 17120-17125. (e) Hengge, A. C.; Onyido, I. Curr. Org. Chem. 2005, 9,61-74. (f) Sorensen-Stowell, K.; Hengge, A. C. J. Org. Chem. 2005, 70, 8303-8308. (g) SorensenStowell, K.; Hengge, A. C. J. Org. Chem. 2005, 70, 4805-4809.

7. (a) Um, I. H.; Han, J. Y.; Hwang, S. J. Chem. Eur. J. 2008, 14, 73247330. (b) Um, I. H.; Shin, Y. H.; Lee, S. E.; Yang, K.; Buncel, E. J. Org. Chem. 2008, 73, 923-920. (c) Um, I. H.; Akhtar, K.; Shin, Y. H.; Han, J. Y. J. Org. Chem. 2007, 72, 3823-3829. (d) Um, I. H.; Park, J. E.; Shin, Y. H. Org. Bionol. Chem. 2007, $5,3539-3543$.

8. Choi, J. H.; Lee, B. C.; Lee, H. W.; Lee, I. J. Org. Chem. 2002, 67, 1277-1282.

9. (a) Um, I. H.; Hong, J. Y; Kim, J. J.; Chae, O. M.; Bae, \$. K. J. Org. Chem. 2003, 68, 5180-5185. (b) Um, I. H.; Chun, S. M.; Chae, O. M.; Fujio, M.; Tsuno, Y. J. Org. Chen. 2004, 69, 31663172. (c) Um, I. H.; Kim, J. J.; Kim, M. J.; Kwon, D. S. Bull. Korean Chem. Soc. 1996, $17,353-357$.

10. (a) Tagaki, W; Kurusu, T.; Oae, S. B. Chem. Soc. Jpn. 1969, 42, 2894-2898. (b) Oae, S.; Kiritani, R. B. Chem. Soc. Jpn 1965, 38, 765-770.

II. (a) Williams, A. Ace. Chem. Res. 1989, 22, 387-392. (b) D'Rozario, P.; Smyth, R. L.; Williams, A. J. An. Chem. Soc. 1984, 106, 50275028.

12. (a) Pregel, M. J.; Dunn, E. J.; Buncel, E. J. Am. Chem. Soc. 1991, 113, 3545-3550. (b) Pregel, M. J.; Dunn, E. J.; Buncel, E. Can. J. Chem. 1990, 68, 1846-1858.

13. Um, I. H.; Lee, S. J.; Kim, J. J.; Kwon, D. S. Bull. Korean Chem. Soc. 1994, 15, 473-477.

14. Buncel, E.; Um, I. H.; Hoz, S. J. An. Chent Soce 1989, II1, 971 -975.

15. (a) Gresser, M. J.; Jencks, W. P. J. Am. Chem. Soc. 1977, 99, 69636970. (b) Gresser, M. J.; Jencks, W. P. J. Am. Chem. Soc. 1977, 99 , $6970-6980$.

16. (a) Um, I. H.; Seo, J. A.; Lee, H. M. Bull. Korean Chent. Soc. 2008, 29, 1915-1919. (b) Um. I. H.; Seo, J. A.; Chun. S. M. Bull. Korean Chem. Soc. 2008, 29, 1459-1463. (c) Um, I. H.; Akhtar, K. Bull. Korean Chem. Soc. 2008, 29, 772-776.

17. (a) Tsuno, Y.; Fujio, M. Atw. Phys. Org. Chem, 1999, 32, 267-385. (b) Tsuno, Y.; Fujio, M. Chem. Soc. Rev, 1996, 25, 129-139. (c) Yukawa, Y.; Tsuno, Y. Btill. Chem. Soc. Jph. 1959, 32, 965-970. 